Voix et Images

voixetimages

\title{
Bibliographie de Madeleine Gagnon
}

Volume 8, numéro 1, automne 1982

Madeleine Gagnon

URI : https://id.erudit.org/iderudit/200365ar

DOI : https://doi.org/10.7202/200365ar

Aller au sommaire du numéro

Éditeur(s)

Les Presses de l'Université du Québec

ISSN

0318-9201 (imprimé)

1705-933X (numérique)

Découvrir la revue

Citer ce document

(1982). Bibliographie de Madeleine Gagnon. Voix et Images, 8(1), 53-58.

https://doi.org/10.7202/200365ar

Ce document est protégé par la loi sur le droit d'auteur. L'utilisation des services d'Érudit (y compris la reproduction) est assujettie à sa politique d'utilisation que vous pouvez consulter en ligne.

https://apropos.erudit.org/fr/usagers/politique-dutilisation/
Cet article est diffusé et préservé par Érudit.

Érudit est un consortium interuniversitaire sans but lucratif composé de l’Université de Montréal, l'Université Laval et l'Université du Québec à Montréal. Il a pour mission la promotion et la valorisation de la recherche. https://www.erudit.org/fr/ 


\section{Bibliographie de Madeleine Gagnon}

\section{A. Livres}

Les Morts-vivants. Nouvelles, Montréal, Éditions HMH, 1969, 175 p. (l'Arbre); Montréal, VLB éditeur, 1982 (à paraître).

Pour les femmes et tous les autres, avec deux illustrations de l'auteur, Montréal, l'Aurore, 1974, 51 p. (Lecture en vélocipède).

Portraits du voyage (en collaboration avec Jean-Marc Piotte et Patrick Straram le Bison ravi), Montréal, l'Aurore, 1974, 95 p. (Écrire).

Poélitique, Montréal, Les Herbes rouges, $n^{\circ} 26$ (février 1975), non paginé.

La Venue à l'écriture (en collaboration avec Hélène Cixous et Annie Leclerc), Paris, Union générale d'éditions, 1977, 155 p. (10/18 «Féminin futur»)[V.p. 63-116].

Retailles. Complaintes politiques (en collaboration avec Denise Boucher), Montréal, Éditions de l'Étincelle, 1977, $160 \mathrm{p}$.

Antre, Montréal, Les Herbes rouges, nos 65-66 (juillet-août 1978), 52 p.

Lueur. Roman archéologique, Montréal, VLB éditeur, 1979, 165 p. III.

Au coeur de la lettre. Poésies, illustrations de l'auteur, Montréal, VLB éditeur, 1981, $101 \mathrm{p}$.

Autographie 1. Fictions 1970-1980, Montréal, VLB éditeur (à paraître).

Autographie 2. Critiques 1970-1980, Montréal, VLB éditeur (à paraître).

Autographie 3. Lectures 1970-1980, Montréal, VLB éditeur (à paraître).

\section{B. Fictions et poèmes parus dans dds périodiques}

“La Laide» et "Wilfrid-le-quêteux», dans Écrits du Canada français, vol. 25, 1968, pp. 30-56. (Reproduits dans Les Morts-vivants).

"Le testament", dans Châtelaine, vol. X, n 8 (août 1969), pp. 23, 36-38, 40.

"Le Feu", dans Liberté, n० 57 (mai-juin 1968), pp. 160-162. (Reproduit dans L'Anthologie des poèmes de l'année, Montréal, l'Hexagone, 1971).

“Suite pour un Québec libre», dans Liberté, vol. XII, n² 2 (mars-avril 1970), pp. 76-78. «L'autre bord de l'hiver ", dans Écrits du Canada français, vol. 29, 1970, pp. 163-187. "Lina parmi les fous", dans Châtelaine, vol. XIV, $n^{\circ} 10$ (novembre 1973), pp. 56-57, 60.

"Poèmes très lisibles", dans Hobo-Québec, nos 14-15 (janvier 1974), p. 9.

"Préface" (en collaboration avec Jean-Marc Piotte), dans Gilles Groulx, Poèmes, Montréal, Les Herbes rouges, $n^{\circ} 14$ (janvier 1974), non paginé.

"Lecture d'amour dévastatrice», dans CV/11 (University of Manitoba), vol. III, $n^{\circ} 3$ (janvier 1978). 
«J'écris», dans Anthologie d'écritures québécoises, Toronto, Coach House Press, 1978.

«Le temps de l'inédit», dans Actue/s (France), 1980.

*Matrie», dans Osiris (U.S.A.), n० 11, 1980.

"A peine une heure», dans La Nouvelle Barre du jour, n० 106 (octobre 1981), pp.6976.

"Si j'écris», dans Au fond des yeux. 20 femmes du Québec qui écrivent, préface de Lise Payette, photographies de Kéro, Montréal, Nouvelle Optique, 1981, 109 p. [V. pp. 30-33].

«L'écriture malgré tout», dans Dérives, $n^{\circ} 33$ (2e trimestre 1982), pp. 6-12.

«Pourquoi j'écris, dans Québec français, $n^{\circ} 47$ (septembre 1982).

\section{Articles}

"Le symbolisme littéraire», dans Symbole. Carrefour interdisciplinaire, (sous la direction de Renée Legris et Pierre Pagé), Montréal, les Éditions Sainte-Marie, 1969,160 p. (Recherche symbolique, $n^{\circ} 1$ ).

«Un aspect du symbolique structural des Cinq grandes odes», I'OEuvre littéraire et ses significations, Montréal, les Presses de l'Université du Québec, 1970. pp. 91-123.

«Angéline de Montbrun: le mensonge historique et la subversion de la métaphore blanche", dans Voix et Images du pays, vol. V (1972), pp. 57-68.

"Productions culturelles et Lutte de classes", dans Socialisme québécois, n 24 (1er trimestre 1974), pp. 63-77.

"La Femme et le langage: sa fonction comme parole et comme manque", dans La Barre du jour, $\mathrm{n}^{\circ} 50$ (hiver 1975), pp. 45-57.

"La Critique d'André Brochu ou la Mise en crise d'une littérature», dans Livres et Auteurs québécois, 1974, pp. 192-196.

« «ssayer de saisir cet instant entre raison et folie, cette lutte, moment décisif...» (Emma Santos)», dans Chroniques, vol. I, $n^{\circ} 1$ (janvier 1975), pp. 38-42.

«Libération de la femme et Lutte de classes» (en collaboration avec Thérèse Arbic), dans Chroniques, vol. I, n² (février 1975), pp. 2-7.

«Entretien. Dora et Portraits du soleil. Hélène Cixous» (en collaboration avec Philippe Haeck et Patrick Straram le Bison ravi), dans Chroniques, vol. I, $n^{\circ} 2$ (février 1975), pp. 16-25.

«Les Communistes américaines et la Lutte des femmes, dans Chroniques, vol. I, $n^{\circ} 2$ (février 1975), pp. 34-36.

"Les Ratés du système: I'asile, la prison», dans Chroniques, vol. I n 3 (mars 1975), pp. $37-41 ; n^{\circ} 4$ (avril 1975), pp. 29-33.

"Elle est objet du sujet elle, ou l'histoire de l'Autre», dans le Devoir, vol. LXVII, n० 107 (10 mai 1975), p. 19.

«L'avortement: encore une affaire de classe», dans Chroniques, vol. I, $n^{\circ} 5$ (mai 1975), pp. 26-29.

"Le journal ASTEUR: un exemple d'écriture militante», dans Chroniques, vol. I, n० 6-7 (juin-juillet 1975), pp. 122-126. 
«Pourquoi, pour qui, comment écrire?», dans Chroniques, vol. I, nos 6-7 (juin-juillet 1975), pp. 122-126.

«Notes critiques sur 'Le Drame de l'enseignement du français' [de Lysiane Gagnon ]. II», dans Chroniques, vol. I, nos 8-9 (août-septembre 1975), pp. 126-131.

«Entre folie et vérité», dans Chroniques, $n^{\circ} 10$ (octobre 1975), pp. 37-42; n० 11 (novembre 1975), pp. 36-40; no 12 (décembre 1975), pp. 32-36.

"Sur la langue», dans Chroniques, $n^{\circ} 12$ (décembre 1975), pp. 15-18.

"Informations [...] Hélène Cixous 2", dans Chroniques, n 12 (décembre 1975), pp. 77-78.

«Stratégie: un exemple de dogmatisme», dans Chroniques, $n^{\circ} 13$ (janvier 1976), pp. 20-43.

"Une rencontre différente des autres», dans Chroniques, $n^{\circ} 13$ (janvier 1976), pp. 59-62.

"Histoire d"O», dans Chroniques, n 14 (février 1976), pp. 56-61.

"Si elle se mettait à parler", dans Chroniques, n 15 (mars 1976), pp. 33-38.

"D'une nef à l'autre», dans Chroniques, n 16 (avril 1976), pp. 30-37.

Écriture/Parole. Atelier animé par Madeleine Gagnon», dans Chroniques, $n^{\circ} 17$ (mai 1976), pp. 8-25.

«Un après-midi, à Villetaneuse, le 1er mai 1976", dans Chroniques, n० 18-19 (juin-juillet 1976), pp. 3-5.

"Le Viol", dans Chroniques, n²2 (octobre 1976), pp. 66-75.

"Pour les femmes et tous les autres», dans Change. Souverain Québec, nos 30-31 (mars 1977), pp. 136-139.

"Des mots pleins la bouche", dans La Barre du jour, nos $56-57$ (mai-août 1977). pp. 139-147. (Traduit dans A Room of one's own (Vancouver), septembre 1978.

"La mort du texte en moi, maintenant le lieu de sa lecture», dans Chroniques, nos 29-30-31-32 (automne 1977-hiver 1978), pp. 210-215.

.Lueur (Pré-texte)", dans Interprétation, n² 21 (printemps 1978), pp. 69-70.

«Dire ces femmes d'où je viens», dans Le Magazine littéraire, $n^{\circ} 134$ (mars 1978), pp. 94-96.

«Femmes du Québec, un mouvement et des écritures» (en collaboration avec Mireille Lanctôt), dans Le Magazine littéraire, n 134 (mars 1978), pp. 97-99.

"La femme et l'écriture. Actes de la Rencontre québécoise internationale des écrivains", dans Liberté, vol. XVII, n 4 (juillet-octobre 1978), pp. 249-254. (Suivi d'une discussion, pp. 254-285).

"Elle m'a parlé de son sang...», dans Sorcières, (septembre 1978).

"Une mémoire déchirée de Thérèse Renaud et Une voix pour Odile de France Théorêt», dans Voix et Images, vol. IV, nº 1 (septembre 1978), pp. 143-146.

"Quand le pouvoir patriarcal s'en prend aux fées", dans Le Devoir, vol. LXIX, n० 285 (8 décembre 1978), p. 5.

"L'infante immémoriale», dans Possibles, vol. IV, n 1 (automne 1979), pp. 83-92.

«Écriture. Sorcellerie. Féminité», dans Études littéraires, vol. $\mathrm{XI}, \mathrm{n}^{\circ} 3$ (décembre 1979), pp. 357-361.

"Lecture de Naissances. De l'écriture québécoise», dans Voix et Images, vol. IV, $\mathrm{n}^{\circ} 3$ (printemps 1981), pp. 393-396. 


\section{CHOIX D'ÉTUDES CONSACRÉES AUX ÉCRITURES DE MADELEINE GAGNON}

\section{A. Les Morts-vivants}

DUCIAUME, Jean-Marcel, "Les Morts-vivants de Madeleine Gagnon-Mahoney", dans Livres et Auteurs québécois, 1969, pp. 52-53.

MAJOR, André, «Leméac, Frye, les morts-vivants, les autres», dans Le Devoir, vol. LX, n०266 (15 novembre 1969), p. 10.

PAUL, Françoise, "Les morts-vivants se portent bien», dans L'Action, vol. LXII, $n^{\circ} 18,935$ (22 novembre 1969), p. 18.

\section{B. Pour les femmes et tous les autres}

BEAUSOLEIL, Claude, "En bref: d'autres textes», dans Hobo-Québec, nos 21-22 (janvier-février/mars-avril 1975), p. 5.

DOSTIE, Gaëtan, «Des poètes mis à jour», dans Le Jour, vol. II, nº 14 (15 mars 1975), p. 12.

HAECK, Philippe, "La Poésie en 1974», dans Chroniques, vol. I, $n^{\circ} 3$ (mars 1975), pp. 44-45.

“D'André Roy à Madeleine Gagnon", dans Le Devoir, vol. LXVII, n 68 (22 mars 1975), p. 15.

JACQUES, Réjean, «Pour les femmes et tout I'monde», dans La Presse, vol. XCI, $n^{\circ} 81$ (5 avril 1975), p. D-6.

C. Portraits du voyage

CHASSÉ, Hélène, «Portraits du voyage», dans Livres et Auteurs québécois, 1975, p. 87.

HAECK, Philippe, "La Tête me brûle», dans Chroniques, vol. I, n 4 (avril 1975), pp. 34-38.

\section{Poélitique}

FISETTE, Jean, «Poélitique de Madeleine Gagnon», dans Voix et Images, vol. I, n०3 (avril 1976), pp. 454-455.

HAECK, Philippe, "Être au service d'une cause: honorable mais difficile», dans Le Devoir, vol. LXVII, no 107 (10 mai 1975), p. 24.

JACQUES, Réjean, "Changer les mots et la politique», dans $L a$ Presse, vol. XCl, $n^{\circ} 159$ (5 juillet 1975), p. D-4.

ROY, André, «La Poésie actuelle ou le Joual qui fuit au galop et revient de temps en temps brouter", dans Le Jour, vol. II, n 159 (11 septembre 1975), p. 8.

\section{E. La Venue à l'écriture}

GODARD, Barbara, "La Venue à l'écriture», dans Waves, 1977, pp. 77-80.

OUELLETTE-MICHALSKA, Madeleine, "Les Intelligentes...», dans Châtelaine, vol. XVIII, n' 10 (octobre 1977), p. 8.

ROY, Monique, «Pour les femmes et les autres", dans Le Devoir, vol. LXIX, n 121 (28 mai 1977), p. 13. 


\section{F. Retailles}

[Anonyme], "Noir sur blanc", dans Dérives, n 10-11 (4e trimestre 1977), pp. 61-62. ARCHAMBAULT, Hélène, "Une belle et longue histoire d'amour», Bibliothèque nationale du Québec, vol. II, $\mathrm{n}^{\circ} 42$ (1977).

BEAUCHAMP, Colette, «les Québécoises écrivent une parole autre puisée dans leur corps et leur sensualité", dans Le Jour, vol. I, n 25 (22 juillet 1977), p. 5.

BIRON, Paule, "Quand l'atmosphère est à la poésie», dans Le Devoir, vol. LXIX, $n^{\circ} 257$ (8 novembre 1977), p. 19.

C., Fr., "Denise Boucher et Madeleine Gagnon, Retailles», dans les Cahiers du Grif, (septembre 1977).

GODBOUT, Jacques, «Des femmes et des revues", dans L'Actualité, vol. II, $n^{\circ} 9$ (septembre 1977), p. 66.

MARTIN, Agathe, "Denise Boucher et Madeleine Gagnon. Retailles», dans Livres et Auteurs québécois, 1977, pp. 75-78.

NATHAN-MURAT, Mireille, Françoise FILLINGER et Nadja RINGART, «Retailles de Denise Boucher et Madeleine Gagnon. II a neigé sur yesterday», dans Libération, (9 mars 1978).

ORENSTEIN, Gloria Feman, «Ecstasy and Tenderness: a feminist reclaiming of love», dans Book Forum, vol. IV, n 1 (1978), pp. 92-98.

OUELLETTE-MICHALSKA, Madeleine, "Les Intelligentes...", dans Châtelaine, vol. XVIII, $n^{\circ} 10$ (octobre 1977), p. 8 :

ROY, Monique, "Retailles», dans Le Devoir, vol. LXIX, n 133 (11 juin 1977), p. 16.

SEFRIOUI, Anne, "Québécoises debouttes", dans les Nouvelles littéraires, vol. LV. $n^{\circ} 2613$ (1er au 8 décembre 1977), p. 20.

TOUGAS, Claudette, "Retailles de deux femmes qui parlent», dans La Presse, vol. XClil, $n^{\circ} 150$ (25 juin 1977), p. D-4.

\section{G. Antre}

BÉDARD, Nicole, «Antre», dans Livres et Auteurs québécois, 1978, pp. 118-120.

BETTINOTTI, Julia, "Madeleine Gagnon. Antre», dans Voix et Images, vol. IV. $n^{\circ} 3$ (avril 1979), p. 543-545.

BONENFANT, Joseph, "Différence de la poésie», dans Le Devoir, vol. LXIX, n²38 (14 octobre 1978), p. 23.

CORRIVEAU, Hugues, «Le Plaisir efficace jusqu'à l'Antre de Madeleine Gagnon», dans Le Devoir, vol. LXIX, no 302 (30 décembre 1978), pp. 11-12.

NEPVEU, Pierre, “La Poésie au féminin. L'Antre et la Sorcière. Madeleine Gagnon et Francine Déry", dans Lettres québécoises, n 12 (novembre 1978), pp. 15-16.

H. Lueur

CORRIVEAU HUGUES, "Des lueurs aveugles», dans Spirale, $n^{\circ} 1$ (septembre 1979). p. 9.

CHAMBERLAND, Roger, "Lueur, de Madeleine Gagnon", dans Livres et Auteurs québécois, 1979, pp. 44-46.

ÉMOND, Maurice, "Lueur. Roman archéologique", dans Québec français, n 35 (octobre 1979), pp. 10-12. 
LAPIERRE, René, "Du meilleur et du pire: auteur de Lueur de Madeleine Gagnon, dans Liberté, vol. 21, $n^{\circ} 6$, novembre-décembre 1979, pp. 128-134.

MÉLANÇON, Robert, "Pour réinventer le monde», dans Le Devoir, vol. LXX, n 122 (26 mai 1979), p. 19.

ROYER, Jean, «Madeleine Gagnon. Explorer les premières traces du langage», dans Le Devoir, vol. LXX, n 122 (26 mai 1979), pp. 17, 18.

VANASSE, André, «Nouveaux romans?", dans Lettres québécoises, n० 15, aoûtseptembre 1979, pp. 14-16.

\section{Au cour de la lettre}

BAYARD, Caroline, "La lettre et l'Ô, vertige et utopie", dans Lettres québécoises, $n^{\circ} 26$, été 82 , pp. 37-40.

BEAULIEU, Ivanhoé, "Madeleine Gagnon et le mystère de l'écriture", dans La Presse, vol. XCVIII, n 49 (27 février 1982), p. C-2.

BEAUSOLEIL, Claude, "La Lettre d'amour", dans Le Devoir, vol. LXXIII, n० 78 (3 avril 1982), pp. 17, 31 .

COTNOIR, Louise, “Une écriture traversière», dans Spirale, $n^{\circ} 23,123$ mars 1982), p. 5. 